\title{
Effect of indoor nitrogen dioxide on lung function in urban environment
}

\author{
Fabio Cibella ${ }^{\mathrm{a}, *}$, Giuseppina Cuttitta ${ }^{\mathrm{a}}$, Roberto Della Maggiore ${ }^{\mathrm{b}}$, Silvia Ruggieri ${ }^{\mathrm{a}}$, \\ Simona Panunzi ${ }^{c}$, Andrea De Gaetano ${ }^{c}$, Salvatore Bucchieri ${ }^{\mathrm{a}}$, Gaspare Drago ${ }^{\mathrm{a}}$, \\ Mario R. Melis ${ }^{\text {a }}$, Stefania La Grutta ${ }^{\text {a }}$, Giovanni Viegi ${ }^{\text {a }}$ \\ a National Research Council of Italy, Institute of Biomedicine and Molecular Immunology, Palermo, Italy \\ ${ }^{\mathrm{b}}$ National Research Council of Italy, Institute of Information Science and Technologies, Pisa, Italy \\ ${ }^{\mathrm{c}}$ National Research Council of Italy, Institute for System Analysis and Computer Science "Antonio Ruberti", Roma, Italy
}

\section{A R T I C L E I N F O}

\section{Article history:}

Received 1 October 2014

Received in revised form

28 January 2015

Accepted 29 January 2015

Available online 13 February 2015

Keywords:

Indoor nitrogen dioxide

Respiratory diseases

Adolescents' health

Questionnaire

Spirometry

\begin{abstract}
A B S T R A C T
Background: High levels of indoor $\mathrm{NO}_{2}$ are associated with increased asthma symptoms and decreased expiratory peak flows in children. We investigated the association of exposure to domestic indoor $\mathrm{NO}_{2}$, objectively measured in winter and spring, with respiratory symptoms and lung function in a sample of adolescents from a southern Mediterranean area.

Methods: From a large school population sample $(n=2150)$ participating in an epidemiological survey in the urban area of the City of Palermo (southern Italy), a sub-sample of 303 adolescents was selected which furnished an enriched sample for cases of current asthma. All subjects were evaluated by a health questionnaire, skin prick tests and spirometry. One-week indoor $\mathrm{NO}_{2}$ monitoring of their homes was performed by diffusive sampling during spring and again during winter.

Results: We found that about $25 \%$ of subjects were exposed to indoor $\mathrm{NO}_{2}$ levels higher than the $40 \mu \mathrm{g} / \mathrm{m}^{3}$ World Health Organization limit, during both spring and winter. Moreover, subjects exposed to the highest indoor $\mathrm{NO}_{2}$ concentrations had increased frequency of current asthma $(p=0.005)$, wheeze episodes in the last 12 months $(p<0.001)$, chronic phlegm $(p=0.013)$, and rhinoconjunctivitis $(p=0.008)$. Finally, subjects with a personal history of wheeze ever had poorer respiratory function $\left(\mathrm{FEF}_{25-75 \%}, p=0.01\right)$ when exposed to higher indoor $\mathrm{NO}_{2}$ concentrations.

Conclusions: Home exposure to high indoor $\mathrm{NO}_{2}$ levels frequently occurs in adolescents living in a southern Mediterranean urban area and is significantly associated with the risks for increased frequency of both respiratory symptoms and reduced lung function.
\end{abstract}

(c) 2015 Elsevier Inc. All rights reserved.

\section{Introduction}

Nitrogen dioxide $\left(\mathrm{NO}_{2}\right)$ is a gaseous substance produced during combustion processes using air as an oxidant. Automobile exhaust, emissions from power plants powered by fossil fuels, and refineries are the most common sources of outdoor $\mathrm{NO}_{2}$. The indoor $\mathrm{NO}_{2}$ concentration depends on both the outdoor concentration and indoor emissions (Cyrys et al., 2000; Breysse et al., 2010), as well as air exchange rates (Sakai et al., 2004). In indoor environments, $\mathrm{NO}_{2}$ emission is mainly due to combustion processes, such as unvented combustion appliances (e.g., gas stoves), vented appliances with defective installations, and tobacco smoke. Exposure to low indoor levels of $\mathrm{NO}_{2}$ is associated with increased frequency

\footnotetext{
* Corresponding author. Fax: +390916809122.

E-mail address: fabio.cibella@ibim.cnr.it (F. Cibella).
}

of reported respiratory symptoms (van Strien et al., 2004). Moreover, higher levels of indoor $\mathrm{NO}_{2}$ are associated with increased asthma symptoms and decreased expiratory peak flows in children (Kattan et al., 2007). Despite higher levels of outdoor $\mathrm{NO}_{2}$ levels found during cold months (January-February) (AMIA SpA, 2007), in a recent study, warmer weather was found to increase the risk of respiratory health effects due to motor vehicle-related $\mathrm{NO}_{2}$ pollution (Tramuto et al., 2011).

Since the indoor concentration of $\mathrm{NO}_{2}$ may be even more elevated than outdoor levels (Lee et al., 2002), there has been increased interest in recent decades in indoor $\mathrm{NO}_{2}$ pollution, and various research programs on the health effects of indoor air quality have been developed worldwide, regarding both school (Simoni et al., 2010, 2011) and domestic (Gillespie-Bennett et al., 2011; Belanger et al., 2013) indoor environments. Children spend most of their time each day in indoor environments (Klepeis et al. 2001), and it appears that exposure to higher home indoor - and 
not outdoor $-\mathrm{NO}_{2}$ levels is associated with an increased frequency of respiratory symptoms and poorer respiratory function in asthmatic children (Gillespie-Bennett et al., 2011). Nevertheless, in the Mediterranean area of southern Europe, data on the effects of indoor $\mathrm{NO}_{2}$ - measured in general population samples of indoor residential settlements in urban environments - on respiratory symptoms and pulmonary function are scanty.

Aims of the present study were to investigate the possible association between $\mathrm{NO}_{2}$ indoor concentrations (objectively measured in spring and winter) and both environmental and home factors; and to investigate the effect of exposure to domestic indoor and outdoor $\mathrm{NO}_{2}$ on respiratory symptoms and lung function on a sample of adolescents in southern Italy.

\section{Materials and methods}

\subsection{Population sample}

In 2005-2006, a cross-sectional epidemiological survey was performed on a population sample of 2150 schoolchildren, aged 10-17 years, from 16 schools in Palermo, a city of 650,000 inhabitants in the Mediterranean area of southern Italy (Cibella et al., 2011). The schoolchildren were investigated by means of a respiratory questionnaire, skin prick tests (SPT), and spirometry. From the original population of 2150 subjects, 323 individuals (14.0\%) were selected for cross-sectional $\mathrm{NO}_{2}$ home monitoring.

Because of the small prevalence of current asthma in the original population (4.2\%), all the current asthma cases were asked to participate in the study for home monitoring (independently of the presence of rhinoconjunctivitis), giving rise to an enriched sample for current asthma with respect to non-current asthma cases. The current asthma cases who decided not to participate did not enter the studied sample and the final sample percentage of current asthma cases was $8.9 \%$, versus $4.2 \%$ of the original population sample.

A subsample of non-current asthma cases was selected, for entry in the home monitoring study, according to the following procedure: after geolocalization of all subjects' addresses through a Geographical Information System, the whole city area was partitioned into $1 \mathrm{~km}$-square grids, and a subset of the subjects in each square was randomly chosen weighing the probability of being sampled for each subject so as to maintain the rhinoconjunctivitis prevalence in each square close to that of the larger sample in the same square (see Table 1 for more details). In this way, a representative sample of the original population for major respiratory symptoms was obtained. Sampled houses were then grouped into three different areas of the city: Centre, North, Suburbs (Fig. 1). Houses located outside the city beltway were included in the latter group.

We avoided selecting multiple subjects with the same address. A large number of back-up candidates was also selected, in order to have ready replacements for any subjects refusing to participate in the study.

The final sub-sample was studied between April 2007 and February 2009 by questionnaires, spirometry, skin prick tests and indoor and outdoor $\mathrm{NO}_{2}$ measurements. The current report is based on analyses of 303 cases.

\subsection{Questionnaire}

Subjects answered a questionnaire concerning their personal history of disease and respiratory symptoms. The same two "core" questionnaire modules of ISAAC for 13-14 year olds (wheezing and rhinitis) (Asher et al., 1995) and the criteria for current asthma and rhinoconjunctivitis definitions were the same as those used in the
Table 1

General characteristics of the sample and those relevant to the original population sample.

\begin{tabular}{|c|c|c|c|}
\hline & $\begin{array}{l}\text { Present } \\
\text { study }\end{array}$ & $\begin{array}{l}\text { Original population } \\
\text { sample }\end{array}$ & $p$ Value \\
\hline Total number & 303 & 2150 & \\
\hline Male gender (no., \%) & $147(48.5)$ & $1057(49.2)$ & $0.75^{\mathrm{a}}$ \\
\hline Age, years (mean $\pm S D$ ) & $13.2( \pm 0.6)$ & $12.6( \pm 1.0)$ & $<0.0001^{\mathrm{b}}$ \\
\hline Height, cm (mean \pm SD) & $\begin{array}{l}160.7 \\
( \pm 7.4)\end{array}$ & $154.2( \pm 8.4)$ & $<0.001^{\mathrm{b}}$ \\
\hline Weight, kg (mean \pm SD) & $\begin{array}{l}56.7 \\
( \pm 12.6)\end{array}$ & $51.0( \pm 13.0)$ & $<0.001^{\mathrm{b}}$ \\
\hline BMI, $\mathrm{kg} / \mathrm{m}^{2}($ mean $\pm \mathrm{SD})$ & $21.8( \pm 3.9)$ & $21.3( \pm 4.3)$ & $0.03^{\mathrm{b}}$ \\
\hline Chronic cough (no., \%) & $18(5.9)$ & $117(5.5)$ & $0.76^{\mathrm{a}}$ \\
\hline Wheeze ever (no., \%) & $93(30.5)$ & $466(21.7)$ & $0.0006^{a}$ \\
\hline $\begin{array}{l}\text { Wheeze in the last } 12 \\
\text { months (no., \%) }\end{array}$ & $41(13.5)$ & $225(10.5)$ & $0.12^{\mathrm{a}}$ \\
\hline Rhino-conjunctivitis (no., \%) & $71(23.4)$ & $430(20)$ & $0.26^{\mathrm{a}}$ \\
\hline Current asthma (no., \%) & $27(8.9)$ & $90(4.2)$ & $0.0003^{a}$ \\
\hline Allergic sensitization (no., \%) & $165(54.4)$ & $839(39.2)$ & $<0.0001^{\mathrm{a}}$ \\
\hline $\begin{array}{l}\text { FVC, \% of predicted } \\
\quad(\text { mean } \pm S D)\end{array}$ & $\begin{array}{l}100.7 \\
( \pm 11.7)\end{array}$ & $96.1( \pm 11.9)$ & $<0.0001^{b}$ \\
\hline $\begin{array}{l}\mathrm{FEV}_{1}, \% \text { of predicted } \\
\quad(\text { mean } \pm \mathrm{SD})\end{array}$ & $\begin{array}{l}103.4 \\
( \pm 12.2)\end{array}$ & $99.4( \pm 11.9)$ & $<0.0001^{\mathrm{b}}$ \\
\hline $\begin{array}{l}\mathrm{FEV}_{1} / \mathrm{FVC}, \% \text { of predicted } \\
(\text { mean } \pm \mathrm{SD})\end{array}$ & $\begin{array}{l}102.3 \\
( \pm 7.0)\end{array}$ & $103.1( \pm 6.7)$ & $0.07^{\mathrm{b}}$ \\
\hline $\begin{array}{l}\mathrm{FEF}_{25-75 \%} \% \text { of predicted } \\
\quad(\text { mean } \pm \mathrm{SD})\end{array}$ & $\begin{array}{l}103.2 \\
( \pm 23.1)\end{array}$ & $101.5( \pm 21.6)$ & $0.20^{\mathrm{b}}$ \\
\hline
\end{tabular}

larger survey. In particular, a history of current asthma was defined as a positive answer to the question, "Have you ever had asthma" plus at least one wheeze episode in the previous 12 months. Rhinoconjunctivitis was defined as a positive answer to both questions: "Have you ever had a problem with sneezing, or runny, or blocked nose apart from common cold or flu in the past 12 months" and "In the past 12 months, has this nose problem been accompanied by itching and/or watering eyes" (Cibella et al., 2011).

The presence of chronic cough (as cough for at least 2 months in the last 12 months), chronic phlegm (as phlegm for at least 2 months in the last 12 months), and wheeze episodes ever in life was also investigated.

Moreover, the technician collected information from an adult member of each family about the presence of gas appliances, second-hand smoke exposure (ETS), mould/dampness exposure at home, the number of hours with open windows, number of rooms, type (detached house/condominium) and floor of residence and the number of years spent in the house. In addition, self-reported traffic exposure was recorded as the frequency of trucks passing on the street of residence on weekdays (never/rare/frequent/ constant).

Household crowding index, as a proxy for socioeconomic status, was computed. It was defined as the total number of co-residents per household divided by the total number of rooms, excluding kitchen and bathrooms (Melki et al., 2004).

\subsection{Respiratory function tests and evaluation of allergic sensitization}

Height (in $\mathrm{cm}$ ) and weight (in $\mathrm{kg}$ ) were measured in standing position without shoes, using a stadiometer and an electronic digital scale for all the children. Pulmonary function tests were performed through a portable spirometer (MicroLoop, Micro Medical, Chatham Maritime, Kent, UK). Forced expiratory volume in $1 \mathrm{~s}\left(\mathrm{FEV}_{1}\right)$ and forced vital capacity (FVC) were measured according to ATS/ERS guidelines (Miller et al., 2005): the best FVC and $\mathrm{FEV}_{1}$ were retained and $\mathrm{FEV}_{1} / \mathrm{FVC}$ computed, and $\mathrm{FEF}_{25-75 \%}$ was selected from the manoeuvre with the largest sum of $\mathrm{FEV}_{1}$ 


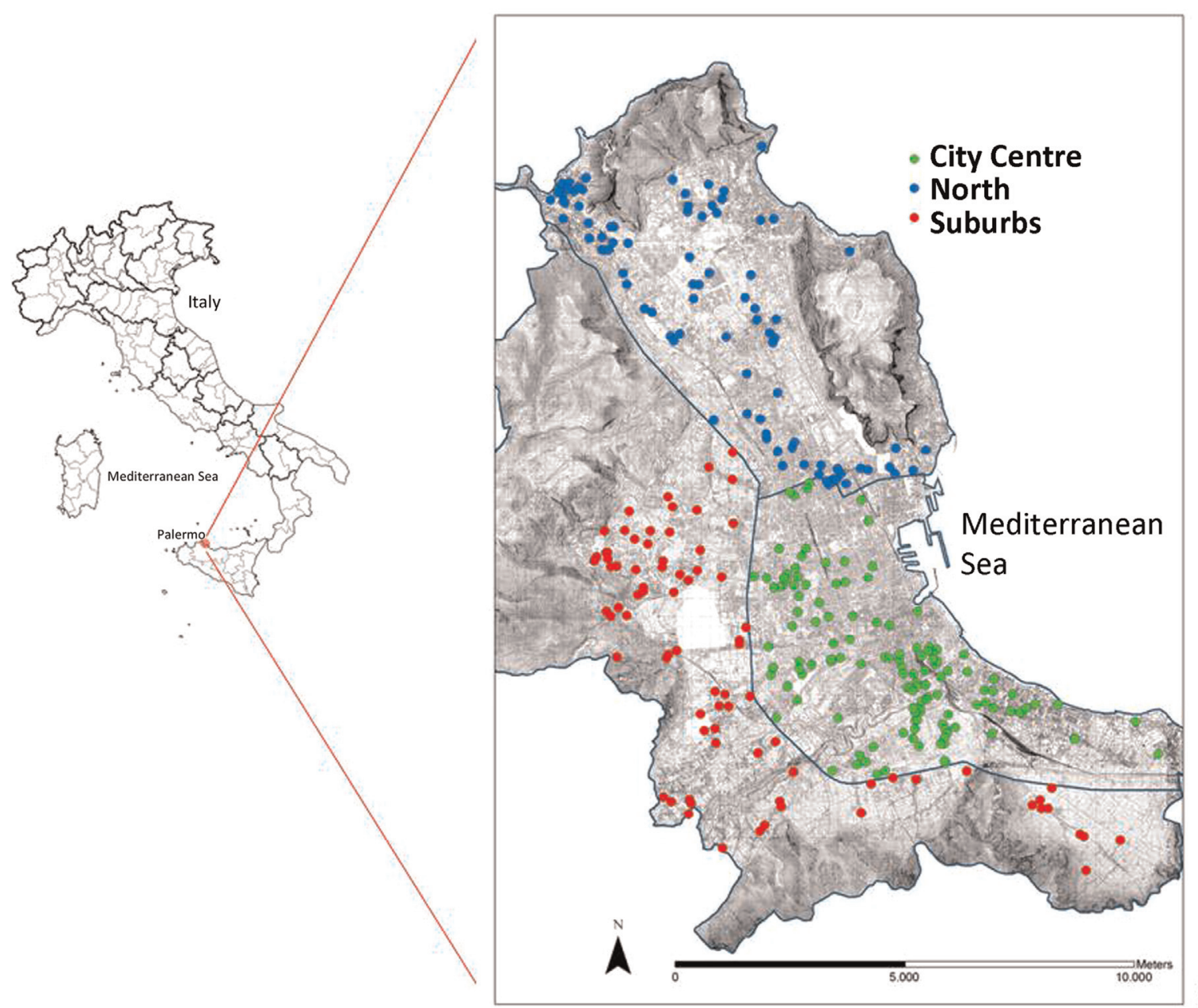

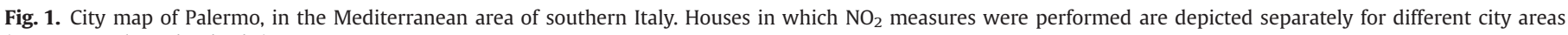
(Centre, North, and Suburbs).

and FVC. Spirometric predicted values were those obtained by the Global Lung Initiative (Quanjer et al., 2012).

Skin prick tests were performed according to EAACI recommendations (The European Academy of Allergology and Clinical Immunology, 1993), with a standard panel including Dermatophagoides mix, grass mix, Parietaria judaica, olive, dog and cat dander, Alternaria alternata, and Blattella germanica, plus a positive (histamine 1\%) and a negative (saline) control (Stallergènes Italia S. r.l., Milan, Italy). Readings were performed after 15 min: reactions were considered positive if the mean wheal diameter (computed as the maximum diameter plus its orthogonal divided by 2) was $3 \mathrm{~mm}$ or greater, after having subtracted the wheal diameter of the reaction to the negative control. Allergic sensitization was defined as the presence of at least one positive skin prick test.

\subsection{Monitoring of indoor and outdoor $\mathrm{NO}_{2}$}

Monitoring of indoor and outdoor $\mathrm{NO}_{2}$ was performed over one week during spring (April-May) and winter months (JanuaryFebruary) in the period indicated above.

We used Radiello ${ }^{\circledR}$ radial diffusive samplers, manufactured by Fondazione Salvatore Maugeri (Padua, Italy), consisting of a microporous cylindrical diffusive body (RAD120-1) containing an absorbent polyethylene cartridge coated with triethanolamine (RAD166). The Radiello ${ }^{\circledR}$ for indoor sampling was placed in the main living area (Belanger et al., 2006), the one for outdoor sampling was placed outside (e.g., at a window or on the balcony).
The exact times of Radiello ${ }^{\circledR}$ placement and removal were recorded for determining the time of exposure. Once collected, absorbent cartridges were stored in the dark at $4{ }^{\circ} \mathrm{C}$ and analysed within 2 months of exposure. Two "blank", unexposed cartridges were retained for reference for each cartridge batch. The analyses of the absorbent cartridges were performed by Fondazione Maugeri laboratories (Padua, Italy). Mean $\mathrm{NO}_{2}$ concentration was expressed as $\mu \mathrm{g} / \mathrm{m}^{3}$.

\subsection{Statistical analysis}

All continuous variables are reported as mean and standard deviations, categorical variables as absolute number and percentage.

Given the asymmetrical distribution of the $\mathrm{NO}_{2}$ concentrations, after having tested for distributional normality, the variable was transformed into logarithms and an Analysis of Variance for Repeated Measurements (RMANOVA) was conducted on the log- $\mathrm{NO}_{2}$ levels to find which environmental factors most affected its concentrations. The variable "Season" (spring and winter) and the variable "Testing Station" (indoor and outdoor) entered the model as within factors; the variables "City Area" (Centre versus Other) and "Traffic Conditions" (questionnaire self-reported evaluation: never, rare, frequent, and constant) entered the model as between factors.

A regression analysis was used to determine which home factors could impact indoor $\mathrm{NO}_{2}$ levels, in spring and in winter separately. Two regression analyses were performed: one with, the 
other without "outdoor concentrations" as a predictor of "indoor concentrations". Other variables considered were the other home related factors: gas appliances, number of hours of open windows, number of rooms, household crowding index, house type (detached house/condominium), and floor of residence. In each model, a stepwise selection based on the Akaike Information Criterion (AIC) statistics was used, with a search mode operating in both directions (backward and forward).

In the study of the relationship between high level of indoor $\mathrm{NO}_{2}$ concentration and the onset of current asthma, preliminary analyses were performed to assess the potential impact of confounding factors: a $\chi^{2}$ test was used to study the possible association between current asthma and other categorical variables (allergic sensitization, parental history for allergy, and City Area), RMANOVA was used to test mean differences of continuous variables (outdoor and indoor concentrations) between levels of the categorical confounding factor.

The relationship between current asthma and indoor $\mathrm{NO}_{2}$ levels was studied by means of an RMANOVA in which the response variable "indoor $\mathrm{NO}_{2}$ concentrations" was tested for possible differences between asthmatic subjects and non-asthmatic subjects (between factor). Season was considered as the within factor. A logistic regression model (current asthma as response variable and indoor $\mathrm{NO}_{2}$ as dependent one) was not used because the enrichment of the sample would have provided artificial estimates of the relative odds ratio. Therefore, the present analysis is focused on a possible correlation between the variables, without regard to any possible causal links between the two variables.

A Receiver Operating Characteristic (ROC) analysis was performed separately for the two seasons to identify those cut-offs of indoor $\mathrm{NO}_{2}$ concentrations which could possibly represent warning levels for current asthma. A dichotomous variable, representing the exposure to "at risk" $\mathrm{NO}_{2}$ concentrations was built: subjects were considered exposed to "at risk" $\mathrm{NO}_{2}$ concentrations if they were exposed to indoor $\mathrm{NO}_{2}$ values exceeding the spring-cut off or the winter-cut off or both.

The relationship between respiratory symptoms and indoor and outdoor $\mathrm{NO}_{2}$ concentrations was studied by means of an RMANOVA, as explained above, for the variable current asthma. Preliminarily, a $\chi^{2}$ test was used to study the association between current asthma and the other respiratory symptoms likely associated with the presence of current asthma. Binomial tests were performed to verify if the subgroups experiencing one of the analysed symptoms distributed differently in the two levels identified by the dichotomous variable representing the exposure to "at risk" $\mathrm{NO}_{2}$ concentrations. A $\chi^{2}$ test was not used in order to prevent misleading associations (between the symptom and any other variable) due to the sample enrichment procedure: in fact, the proportion of subjects with current asthma with respect to non-current asthma (as well as the proportions related to all the other respiratory symptoms associated with the presence of current asthma) is not representative of the entire population.

Respiratory function variables $\left(\mathrm{FEV}_{1}, \mathrm{FVC}, \mathrm{FEV}_{1} / \mathrm{FVC}\right.$ and $\mathrm{FEF}_{25-75 \%}$ ) were considered as percentage of predicted. Correlations between spirometric variables and indoor $\mathrm{NO}_{2}$ concentrations were computed for both spring and winter.

Respiratory function variables (as percentage of predicted) were also analysed by means of an ANOVA, using the dichotomous variable representing the exposure to "at risk" $\mathrm{NO}_{2}$ concentrations (as derived by the ROC curve) as well as each health symptom (presence/absence), one at time, as a "between" factor. The analysis was aimed at testing whether respiratory function can be affected by high $\mathrm{NO}_{2}$ concentrations when in association with each considered health symptom (interaction term).

Any other association between categorical variables was tested performing a $\chi^{2}$ test, whereas a $t$-test was used to study possible differences of a continuous variable between two levels of a factor.

All analyses were performed in R. A p-Value $<0.05$ was assumed to be statistically significant.

\subsection{Ethics statement}

The study was approved by the Ethical Committee of the University Hospital of Palermo [01/07]. All parents of the invited children signed a written informed consent. According to the Italian law, the respect of individual privacy concerning clinical data was granted.

\section{Results}

In Table 1 the general characteristics of the sample (compared to those relevant to the original population sample) are presented. Due to the time shift between the campaign in which the original population sample was obtained (Cibella et al., 2011) and the present indoor monitoring study, significant differences exist in all the anthropometric variables and in those strongly related to lung size (namely, FVC and $\mathrm{FEV}_{1}$ ). Moreover, because of the sample enrichment in current asthma, the frequency of all the variables associated with allergic sensitization was significantly higher.

Mean (and $\mathrm{SD}, \mu \mathrm{g} / \mathrm{m}^{3}$ ) of $\mathrm{NO}_{2}$ levels during spring were 31.9 $( \pm 14.9)$ indoor and $28.1( \pm 12.7)$ outdoor. The same figures during winter were: $32.2( \pm 16.3)$ indoor and $28.0( \pm 14.5)$ outdoor. In Fig. 2 box plots are presented relevant to the distribution of indoor and outdoor $\mathrm{NO}_{2}$ concentration in both seasons. During spring and winter, $24.5 \%$ and $25.2 \%$ of subjects, respectively, were exposed to indoor $\mathrm{NO}_{2}$ levels higher than the World Health Organization indoor limit of $40 \mu \mathrm{g} / \mathrm{m}^{3}$ (WHO, 2010).

\subsection{Environmental factors and $\mathrm{NO}_{2}$ concentrations}

Results on $\mathrm{NO}_{2}$ concentrations from the RMANOVA showed significance for the main factors of Testing Station, City Area, and Traffic Condition $\left(p<0.001\right.$ in all cases), with higher $\mathrm{NO}_{2}$ concentrations for indoor station (Fig. 3), centre area and constant traffic; no interaction factor was significant, apart from the interaction between "City Area" and "Testing Station" ( $p=0.02)$ : indoor and outdoor $\mathrm{NO}_{2}$ concentrations $\left(\mu \mathrm{g} / \mathrm{m}^{3}\right)$ did not differ in the city centre, 35.2 ( \pm 15.3 ) versus 32.3 ( \pm 12.9 ) respectively; indoor $\mathrm{NO}_{2}$ concentrations were higher than outdoor concentrations in both the North (31.4 $[ \pm 16.3]$ indoor and $28.0[ \pm 14.1]$ outdoor) and

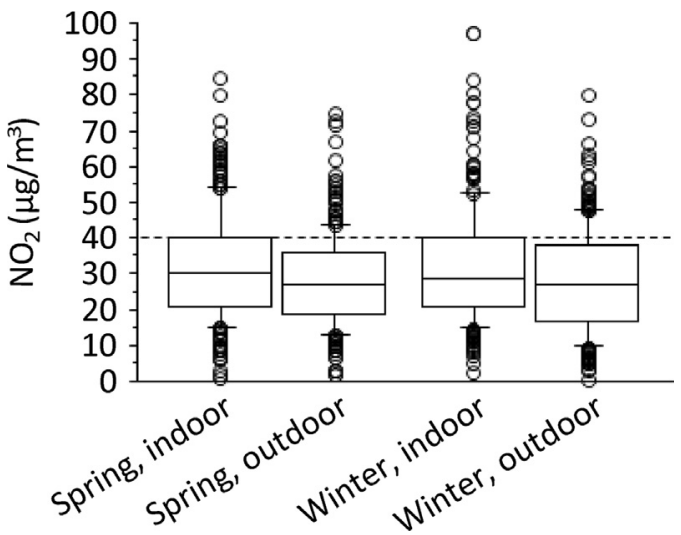

Fig. 2. Distribution of indoor and outdoor nitrogen dioxide $\left(\mathrm{NO}_{2}\right)$ values measured during spring and winter. Bars indicate (from the bottom to the top) 10th, 25th, 50th (median), 75th, and 90th percentiles. Values below 10th and above 90th percentiles are plotted as circles. The WHO maximum annual average indoor $\mathrm{NO}_{2}$ limit $\left(40 \mu \mathrm{g} / \mathrm{m}^{3}\right)$ is depicted. Indoor values were significantly higher than outdoor ones (RMANOVA, $p<0.001$ ), without any effect of season. 


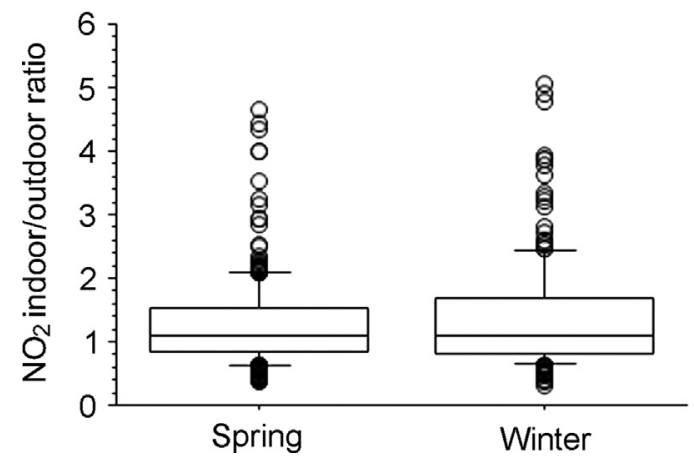

Fig. 3. Distribution of indoor and outdoor $\mathrm{NO}_{2}$ ratio measured during spring and winter. Indoor $\mathrm{NO}_{2}$ concentration was significantly higher than outdoor concentration ( $p<0.001$ by Analysis of Variance for Repeated Measurements model). Bars indicate (from the bottom to the top) 10th, 25th, 50th (median), 75th, and 90th percentiles. Values below 10th and above 90th percentiles are plotted as circles.

Suburbs (27.6 [ \pm 13.7] indoor and $21.1[ \pm 10.9]$ outdoor) areas. No effect of the "Season" factor was evident.

\subsection{Environmental and home factors and $\mathrm{NO}_{2}$ concentrations}

A regression model was built separately for the two seasons: as concerns $\mathrm{NO}_{2}$ indoor concentrations measured in the spring, the final model included $\mathrm{NO}_{2}$ outdoor concentration $(p<0.001)$, house type $(p=0.036)$ and household crowding index $(p=0.093)$ as independent variables. In winter, only two variables entered the final model: winter outdoor concentrations $(p<0.001)$ and house type $(p=0.11)$. In both models, the indoor concentrations increased with an increase of the outdoor concentrations and when the house was of the condominium type. When outdoor concentrations were not considered in the analyses, the only variable included in the final models was the house type, with a $p$ Value less than 0.001 in spring and equal to 0.003 in winter.

\subsection{Relationship between indoor $\mathrm{NO}_{2}$ concentrations and current asthma}

Because, a priori, the population of non-asthmatic children cannot be representative of the entire population (given the sample-enrichment procedure followed in the present study), preliminary tests were used to verify the possible influence of potential confounding factors in the study of the relationship between high levels of indoor $\mathrm{NO}_{2}$ and the onset of current asthma. Among the possible confounding factors, allergic sensitization, parental history for allergy and the City Area (Centre, North, Suburbs) were taken into account. The association between allergic sensitization and current asthma, as well as the association between parental history for atopic diseases and current asthma, were both significant $(p<0.001$ and $p=0.001)$. In fact, the nearly all (92.6\%) subjects with current asthma presented allergic sensitization, and about $37 \%$ of asthmatic subjects presented parental atopy, compared to only $12 \%$ of non-asthmatic individuals. A $\chi^{2}$ test on current asthma and City Area was borderline significant $(p=0.05)$, given that the majority of subjects with current asthma (67\%) live in the city centre where, from a previous analysis, $\mathrm{NO}_{2}$ concentrations appeared to be significantly higher than in other city areas. Preliminary RMANOVA tests were therefore performed in order to verify if outdoor concentrations were significantly different in the two seasons between subjects with and without current asthma (to take into account the different distribution of subjects in the city), and to test simultaneously: i) the difference in the average indoor $\mathrm{NO}_{2}$ concentrations in the two levels of the fixed factors, allergic sensitization and parental history for atopy; ii) the possible interaction between the considered factor and the season. These tests would provide a clue to possible systematic errors due to sampling, which would invalidate results related to any relationship between current asthma and indoor $\mathrm{NO}_{2}$ levels. Outdoor levels to which current asthma and non-current asthma subjects were exposed were not significantly different $(p=0.44)$, and no significant interaction appeared between current asthma and Season $(p=0.18)$. Moreover, results were not significant in either the simple effects or the interaction terms, when allergic sensitization and parental history for atopy were tested: indoor $\mathrm{NO}_{2}$ levels did not differ between subjects with or without allergic sensitization $(p=0.23)$ or between subjects with or without parental atopy $(p=0.69)$.

The RMANOVA, testing the possible difference of indoor $\mathrm{NO}_{2}$ concentrations between subjects with and without current asthma, showed significance of the current asthma factor $(p=0.005)$ : indoor $\mathrm{NO}_{2}$ concentrations were higher for asthmatic subjects both in spring and in winter $(36.7[ \pm 11.6]$ versus $31.5[ \pm 15.1]$ and $44.3[ \pm 25.3]$ versus $31.1[ \pm 14.9] \mu \mathrm{g} / \mathrm{m}^{3}$, respectively).

Results from the ROC analyses identified 28.0 and $41.4 \mu \mathrm{g} / \mathrm{m}^{3}$ as optimal cut off values for indoor $\mathrm{NO}_{2}$ concentrations in spring and winter, respectively. Corresponding to these cut-offs, Sensitivity and Specificity were $81.5 \%$ and $50.0 \%$ in spring, and $60.0 \%$ and
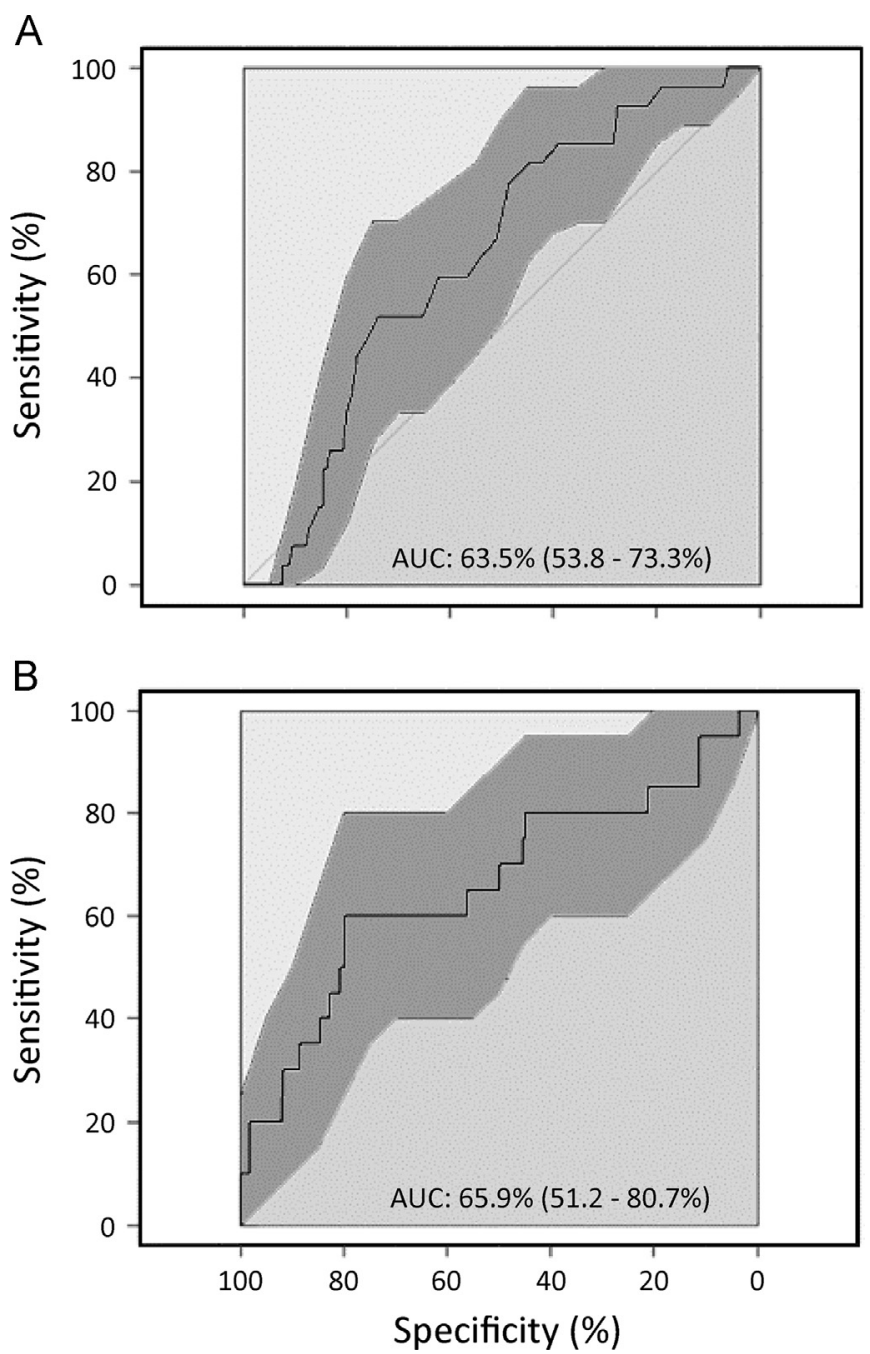

Fig. 4. Receiver operating characteristic curves. Sensitivity and Specificity, related to "at risk" cut-off values for current asthma, of indoor $\mathrm{NO}_{2}$ concentrations in spring (panel A) and in winter (panel B). 
$79.7 \%$ in winter. The areas under the curves were $63.5 \%$ (CI: $53.8-$ $73.3 \%, p=0.02$ ) in spring and 65.9\% (CI: 53.8-73.3\%, $p=0.018$ ) in winter. In Fig. 4, panels A and B report the two ROC curves in spring and winter.

\subsection{Relationship between high levels of indoor $\mathrm{NO}_{2}$ concentrations and respiratory symptoms}

The variables wheeze in the past 12 months, rhinoconjunctivitis and allergic sensitization were strongly associated with current asthma $\left(p<0.001\right.$ from $\chi^{2}$ test). In fact, all subjects with current asthma, due to its definition, presented wheeze in the past 12 months; moreover, $74 \%$ of current asthma individuals had rhinoconjunctivitis and $92.6 \%$ presented allergic sensitization). Thus, when studying the relationships existing among these health conditions (i.e., wheeze in the past 12 months, rhinoconjunctivitis, and allergic sensitization) and indoor $\mathrm{NO}_{2}$ levels, the results may depend on the interaction between the considered symptom and current asthma. The other studied health symptoms were chronic cough and chronic phlegm. When an RMANOVA was used, apart from the expected significant differences in the level of indoor $\mathrm{NO}_{2}$ concentrations between subjects with wheeze in the past 12 months or with rhinoconjunctivitis and subjects without symptoms ( $p=0.003$ and $p=0.02$, respectively), results showed that subjects with chronic phlegm were exposed to significantly $(p=0.032)$ higher levels of indoor $\mathrm{NO}_{2}$ concentrations than subjects without chronic phlegm: $41.1[ \pm 20.5]$ versus $31.5[ \pm 15.0]$ $\mu \mathrm{g} / \mathrm{m}^{3}$, independent of the Season. Table $2 \mathrm{~A}$ and B report the mean values of indoor and outdoor $\mathrm{NO}_{2}$ concentrations respectively, in subjects with and without respiratory symptoms, in spring and in winter. The $p$ Values from RMANOVA related to the symptom are also reported.

By means of the cut-off values identified by ROC analysis ( 28.0 and $41.4 \mu \mathrm{g} / \mathrm{m}^{3}$ in spring and in winter, respectively), each subject could be categorized as exposed or not to indoor $\mathrm{NO}_{2}$ concentrations at risk for current asthma. According to this classification, 174 subjects (57.4\%) out of 303 were determined to be exposed to "at risk" indoor $\mathrm{NO}_{2}$ concentrations. For each health symptom, a binomial test was performed to verify if, within the subgroup where one of the symptoms was present, there was a significant difference in the proportion of subjects belonging to the two levels of the dichotomous variable. Again, tests were significant for current asthma $(p<0.001)$, wheeze in the past 12 months $(p<0.001)$, rhinoconjunctivitis $(p=0.008)$, allergic sensitization $(p=0.019)$ and chronic phlegm $(p=0.013)$. Table 3 reports the distributions of the subjects with the symptoms in each level of the cut-off variable. In Table 4 the distribution of current asthma is presented for each combination of exposure to "at risk" indoor $\mathrm{NO}_{2}$ concentration and of allergic sensitization: almost one fourth of subjects presented current asthma if allergic sensitization was present along with the exposure to "at risk" indoor $\mathrm{NO}_{2}$ concentration.

\subsection{Relationship between high levels of indoor $\mathrm{NO}_{2}$ concentrations and respiratory function}

Correlation between both indoor and outdoor $\mathrm{NO}_{2}$ concentration and the variables relevant to the respiratory function were all non-significant. Conversely, the ANOVA analyses performed on respiratory function, conducted using the exposure to "at risk" $\mathrm{NO}_{2}$ concentrations and each health symptom as "between" factors, showed significant interaction only between $\mathrm{FEF}_{25-75 \%}$ and

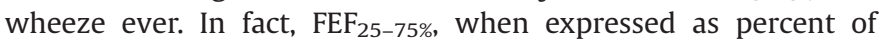
predicted, was significantly smaller in subjects with wheeze ever exposed to at risk indoor $\mathrm{NO}_{2}$ concentration levels: $95.2 \pm 20.0$ versus $110.3 \pm 22.8(p=0.01)$ in the presence and absence of wheeze ever, respectively; on the contrary, values were very similar when subjects were exposed to low $\mathrm{NO}_{2}$ concentrations: $101.1 \pm 23.0$ and $101.1 \pm 23.4$ in the presence and absence of wheeze ever, respectively.

\section{Discussion}

In the present cross-sectional study, more than 300 children were evaluated by a self-administered questionnaire: in addition, objective measures of lung function (spirometry) and individual allergic sensitization (skin prick tests) were performed. At the same time, all their residences were investigated for $\mathrm{NO}_{2}$ environmental pollution (by Radiello ${ }^{\mathbb{R}}$ passive samplers) in order to objectively assess the association between environmental factors and individual's health status.

With regard to the recent recommendation of the World Health Organization of a maximum annual average indoor $\mathrm{NO}_{2}$ limit of $40 \mu \mathrm{g} / \mathrm{m}^{3}$ (WHO, 2010), one of the findings of the present study is that about $25 \%$ of the subjects living in the investigated houses appear to be exposed to indoor $\mathrm{NO}_{2}$ levels higher than this limit, during both spring and winter. To our knowledge, this is the first study estimating indoor exposure to $\mathrm{NO}_{2}$ in domestic environments of a general population in relation to the WHO limit. Moreover, we found that: (1) a positive significant relationship exists between indoor and outdoor $\mathrm{NO}_{2}$ levels during both spring and winter, without any significant effect of season; 2) $\mathrm{NO}_{2}$ levels were higher in the residences located in the city centre than in suburban area; 3 ) both outdoor and indoor $\mathrm{NO}_{2}$ levels were significantly higher in the residences of subjects self-reporting high exposure to truck traffic; 4) exposure to the highest levels of indoor $\mathrm{NO}_{2}$ concentration was associated with an increased prevalence of chronic phlegm, wheeze in the past 12 months, and current asthma; and 5) subjects with a personal history of wheeze ever had poorer respiratory function when exposed to higher indoor $\mathrm{NO}_{2}$ concentration.

In accordance with a previous French study using a similar methodological approach, we found that indoor $\mathrm{NO}_{2}$ level is

Table 2A

Indoor $\mathrm{NO}_{2}$ concentrations $\left(\mu \mathrm{g} / \mathrm{m}^{3}\right.$, mean and $\mathrm{SD}$ ) in the two Seasons in subjects with or without respiratory symptoms.

\begin{tabular}{|c|c|c|c|c|c|}
\hline & \multicolumn{4}{|c|}{ Indoor $\mathrm{NO}_{2}$ concentrations $\left(\mu \mathrm{g} / \mathrm{m}^{3}\right)$} & \multirow[t]{2}{*}{$p$ Value $^{a}$} \\
\hline & $\begin{array}{l}\text { Spring } \\
\text { Yes }\end{array}$ & Winter & $\begin{array}{l}\text { Spring } \\
\text { No }\end{array}$ & Winter & \\
\hline Rhino-conjunctivitis & $34.6( \pm 14.0)$ & $35.5( \pm 17.1)$ & $31.1( \pm 15.1)$ & $31.4( \pm 16.1)$ & 0.02 \\
\hline Chronic phlegm & $42.4( \pm 17.6)$ & $39.4( \pm 24.2)$ & $31.3( \pm 14.5)$ & $31.8( \pm 15.7)$ & 0.032 \\
\hline Chronic cough & $34.7( \pm 12.2)$ & $32.3( \pm 16.3)$ & $31.8( \pm 15.0)$ & $32.2( \pm 16.3)$ & 0.46 \\
\hline Wheeze in the last 12 months & $36.7( \pm 14.1)$ & $40.4( \pm 22.2)$ & $31.2( \pm 14.9)$ & $31.1( \pm 15.1)$ & 0.003 \\
\hline Current asthma & $36.7( \pm 11.6)$ & $44.3( \pm 25.3)$ & $31.5( \pm 15.1)$ & $31.1( \pm 14.9)$ & 0.005 \\
\hline Allergic sensitization & $32.4( \pm 14.7)$ & $32.4(16.4)$ & $31.4( \pm 15.1)$ & $32.0( \pm 16.3)$ & 0.69 \\
\hline
\end{tabular}

${ }^{a} p$ from RMANOVA. 
Table 2B

Outdoor $\mathrm{NO}_{2}$ concentrations $\left(\mu \mathrm{g} / \mathrm{m}^{3}\right.$, mean and $\mathrm{SD}$ ) in the two Seasons in subjects with or without respiratory symptoms.

\begin{tabular}{|c|c|c|c|c|c|}
\hline & \multicolumn{4}{|c|}{ Outdoor $\mathrm{NO}_{2}$ concentrations $\left(\mu \mathrm{g} / \mathrm{m}^{3}\right)$} & \multirow[t]{2}{*}{$p$ Value $^{a}$} \\
\hline & $\begin{array}{l}\text { Spring } \\
\text { Yes }\end{array}$ & Winter & $\begin{array}{l}\text { Spring } \\
\text { No }\end{array}$ & Winter & \\
\hline Rhino-conjunctivitis & $29.2( \pm 12.6)$ & $29.9( \pm 15.4)$ & $27.7( \pm 12.7)$ & $27.5( \pm 14.3)$ & 0.28 \\
\hline Chronic phlegm & $29.9( \pm 14.2)$ & $30.3( \pm 17.1)$ & $28.0( \pm 12.6)$ & $27.9( \pm 14.4)$ & 0.54 \\
\hline Chronic cough & $26.6( \pm 11.3)$ & $25.3( \pm 14.4)$ & $28.2( \pm 12.7)$ & $28.2( \pm 14.6)$ & 0.59 \\
\hline Wheeze in the last 12 months & $29.1( \pm 10.2)$ & $30.8( \pm 17.6)$ & $27.9( \pm 13.0)$ & $27.6( \pm 14.1)$ & 0.24 \\
\hline Current asthma & $29.8( \pm 11.3)$ & $33.7( \pm 19.1)$ & $27.9( \pm 12.8)$ & $27.5( \pm 14.0)$ & 0.19 \\
\hline Allergic sensitization & $29.1( \pm 12.5)$ & $29.6(15.8)$ & $26.8( \pm 12.8)$ & $26.2( \pm 12.9)$ & 0.66 \\
\hline
\end{tabular}

a $p$ from RMANOVA.

Table 3

Distribution of the subjects with respiratory symptoms exposed to "at risk" indoor $\mathrm{NO}_{2}$ concentrations, as evaluated through ROC curve cut-off values.

Number of subjects with symptoms exposed $p^{\text {a }}$ to "at risk" indoor $\mathrm{NO}_{2}$ concentrations/ number of subject with symptoms (\%)

\begin{tabular}{lrr}
\hline Chronic phlegm & $14 / 17(82 \%)$ & 0.013 \\
Chronic cough & $13 / 18(72 \%)$ & 0.096 \\
Allergic sensitization & $98 / 165(59 \%)$ & 0.019 \\
Wheeze in the last 12 & $32 / 41(78 \%)$ & $<0.001$ \\
$\quad$ months & & \\
Rhino-conjunctivitis & $47 / 71(66 \%)$ & 0.008 \\
Current asthma & $24 / 27(89 \%)$ & $<0.001$ \\
\hline
\end{tabular}

${ }^{a} p$ from binomial tests.

\section{Table 4}

Prevalence of current asthma for each combination of exposure to "at risk" indoor $\mathrm{NO}_{2}$ concentration and allergic sensitization. The prevalence of each combination is also displayed.

\begin{tabular}{llll}
\hline No. (\%) & $\begin{array}{l}\text { Exposure to "at risk" of in- } \\
\text { door } \mathrm{NO}_{2} \text { concentration }\end{array}$ & $\begin{array}{l}\text { Allergic } \\
\text { sensitization }\end{array}$ & $\begin{array}{l}\text { Current asth- } \\
\text { ma (\%) }\end{array}$ \\
\hline $62(20.5 \%)$ & No & No & 0.0 \\
$76(25.1 \%)$ & Yes & No & 2.6 \\
$67(22.1 \%)$ & No & Yes & 4.5 \\
$98(32.3 \%)$ & Yes & Yes & 22.4 \\
\hline
\end{tabular}

$\chi^{2}$ for frequency distribution of current asthma was significant $(p<0.001)$.

a Absolute count (and prevalence) of each combination of exposure to "at risk" indoor $\mathrm{NO}_{2}$ concentration and of allergic sensitization.

correlated to outdoor $\mathrm{NO}_{2}$ (Flamant-Hulin et al., 2010). In addition, similarly to previous results (Hansel et al., 2008), we found that indoor $\mathrm{NO}_{2}$ levels are higher than outdoor levels, possibly due to the presence of indoor $\mathrm{NO}_{2}$ sources (Cyrys et al., 2000). Historical data from urban pollution monitoring stations in Palermo show that an increase of outdoor $\mathrm{NO}_{2}$ levels is usually detected during January and February; lower values are usually recorded during spring. Despite these data, we did not find any significant difference between winter and spring in indoor $\mathrm{NO}_{2}$ measures. Thus, elevated indoor $\mathrm{NO}_{2}$ levels may persist without significant seasonal changes: relatively mild winters, typical of the Mediterranean area, with small changes in temperature between summer and winter, might explain this result. Moreover, it must be remembered that Radiello ${ }^{\circledR}$ outdoor measures were performed in the immediate outdoor area of each house, i.e., in a location largely different from that used for environmental monitoring stations.

As concerns outdoor $\mathrm{NO}_{2}$, in the absence of power plants or petroleum refineries close to Palermo, the main sources of fossil fuel pollution are vehicular traffic and ship transportation. Accordingly, we found that outdoor $\mathrm{NO}_{2}$ showed its highest values in the city centre, both in spring and winter, while suburbs presented significantly lower $\mathrm{NO}_{2}$ levels. In view of the correlation between indoor and outdoor $\mathrm{NO}_{2}$ concentrations, residences located in the central urban area also presented higher values for indoor $\mathrm{NO}_{2}$. Thus, living in the central area of the city and in condominiums were determinants for the highest indoor $\mathrm{NO}_{2}$ levels. Conversely, we did not find a significant effect of the presence of gas appliances, number of hours of window opening, number of rooms, household crowding index, and floor of residence on indoor $\mathrm{NO}_{2}$ levels. We did not take into account the presence of "gas fires", but only the presence of indoor sources of gas for the production of hot water and domestic heating: in fact, domestic habits, in Palermo, exclude the use of electric stoves for cooking.

Although the highest $\mathrm{NO}_{2}$ levels are usually found in the kitchen (Simoni et al., 2002), we placed Radiello ${ }^{\circledR}$ passive monitors in the living room because children spend most of their time in this room during daily life at home. Moreover, boys may spend their time in the kitchen differently from girls (Jarvis et al., 1996).

We found a significantly increased indoor $\mathrm{NO}_{2}$ level measured in the houses of subjects reporting high truck traffic near their residence. This result supports the validity of self-reported exposure to vehicular traffic collected by questionnaires. Despite the fact that self-reported air pollution in residential areas appeared to be significantly associated with increased levels of GIS-modelled air pollution, subjects with chronic disease tend to report more air pollution in the residential area (Piro et al., 2008). In the present paper, the use of direct indoor and outdoor measures of a specific pollutant made possible the estimation of exposure/effect relationships, avoiding any reporting bias that might alter the association between reported exposure to road traffic and disease (Kuehni et al., 2006), and supports the utility of questionnairebased exposure information (see also Nuvolone et al., 2011).

We investigated whether poor indoor air quality significantly increases respiratory symptoms using the well-validated questionnaire-based definitions of the ISAAC Study (Asher et al., 1995). Cut-off values for higher $\mathrm{NO}_{2}$ indoor concentration were computed by ROC curves (Fig. 4) to identify, separately for spring and winter, $\mathrm{NO}_{2}$ levels representing a possible risk for respiratory symptoms. Our results support an association between indoor $\mathrm{NO}_{2}$ concentration and respiratory health in adolescents: conversely, as previously reported (Gillespie-Bennett et al., 2011), no significant association with outdoor $\mathrm{NO}_{2}$ concentration was found. In bivariate models, we found that $82 \%$ of children reporting chronic phlegm and $78 \%$ of those with wheeze in the past 12 months were exposed to higher indoor $\mathrm{NO}_{2}$ levels. Also, the presence of current asthma was strongly associated with higher indoor $\mathrm{NO}_{2}$ concentrations. Thus, our results support other studies finding that home exposure to higher indoor $\mathrm{NO}_{2}$ levels is associated with an increased prevalence of lower respiratory symptoms, previously shown both in children from a general population sample (Neas et al., 1991) and in asthmatic children (Kattan et al., 2007; Belanger et al., 2006). A recent meta-analysis has also shown that $\mathrm{NO}_{2}$ increases the risk of current wheeze in children (Lin et al., 2013). It is 
of interest that our results, based on the objective evaluation of i) allergic sensitization and ii) exposure to "at risk" $\mathrm{NO}_{2}$ indoor concentration, show that children presenting both conditions (i.e., allergic sensitization and exposure to high indoor $\mathrm{NO}_{2}$ levels) had a striking increase of the risk for current asthma, up to $22.4 \%$ prevalence (while none of the subjects without allergic sensitization and exposed to lower indoor $\mathrm{NO}_{2}$ levels presented current asthma). Previous reports exist on the possible synergistic action between allergic sensitization and exposure to indoor air pollutants such as $\mathrm{NO}_{2}$ (Flamant-Hulin et al., 2010), even though controversial results exist: in fact, in a previous paper increasing levels of $\mathrm{NO}_{2}$ produced only a small and non-significant increase in the risk of respiratory symptoms in atopic children (Garrett et al., 1998). Interestingly, we found clear evidence that in allergic adolescents with personal history of bronchial asthma the exposure to indoor $\mathrm{NO}_{2}$ is associated with an increased risk of wheeze episodes indicating a possible gene-environment interaction.

Finally, in children presenting both a personal history of wheeze ever and an exposure to higher indoor $\mathrm{NO}_{2}$ concentration we found a significantly lower $\mathrm{FEF}_{25-75 \%}$ with respect to those exposed to lower indoor $\mathrm{NO}_{2}$ levels. This result is in agreement with a previous paper by Gillespie-Bennett et al. (2011) showing the effect of indoor $\mathrm{NO}_{2}$ exposure on asthmatic children in New Zealand. In this paper, $\mathrm{NO}_{2}$ exposure was associated with increased frequency of respiratory tract symptoms and decreased $\mathrm{FEV}_{1}$. Similarly, exposure to environmental $\mathrm{NO}_{2}$ - estimated by means of a land use regression model - was shown to be associated with reduced expiratory flows in schoolchildren (Rosenlund et al., 2009). These results strongly suggest that home exposure to indoor $\mathrm{NO}_{2}$ not only increases the frequency of respiratory symptoms (subjective data), but also impairs lung function (objective data) in children.

\section{Conclusions}

To our knowledge, this is the first study performed in the Mediterranean area evaluating the association between indoor $\mathrm{NO}_{2}$ pollution and respiratory health in adolescents, thus assessing the interaction between individual risk factors and home environments in a warm climate characterized by hot summers with low rainfall and mild winters. In this area, populations have largely different standards of living and lifestyles. Because these differences may act as effect modifiers in the relationship between indoor pollutants and respiratory health, our findings warrant being confirmed in different local settings.

Exposure to high indoor $\mathrm{NO}_{2}$ levels frequently occurs in the residences evaluated in the present survey, and this exposure significantly increases the risk for both respiratory symptoms and reduced lung function. Of particular interest is the interaction between allergic sensitization and environmental $\mathrm{NO}_{2}$ exposure, which yields a very high risk for respiratory morbidity in adolescents. Public health policies aimed at specifically addressing the issue of air pollution in indoor environments should be promoted with a specific focus on possible domestic emissions.

\section{Funding sources}

The present study was supported in part by grants from the Regional Agency for Environmental Protection (ARPA Sicilia) [DDG No. 303/2005 and No. 722/2006].

The Study Sponsor (ARPA Sicilia) had no role in the study design, the collection, analysis, and interpretation of data, the writing of the report, or the decision to submit the paper for publication.

\section{Aknowledgements}

We are grateful to Dr. Claudio Cocheo and Dr. Paolo Sacco, from Fondazione Salvatore Maugeri (Padua, Italy), for their technical assistance in performing Radiello ${ }^{\mathbb{R}}$ analyses.

\section{References}

AMIA SpA, 2007. City of Palermo, 2005-2006 6th Annual Report of Environmental Health Service of Municipality: The Detection of Air and Noise Pollution in the Municipality of Palermo. Dept. of Installations.

Asher, M.I., Keil, U., Anderson, H.R., Beasley, R., Crane, J., Martinez, F., Mitchell, E.A., Pearce, N., Sibbald, B., Stewart, A.W., et al., 1995. International Study of Asthma and Allergies in Childhood (ISAAC): rationale and methods. Eur. Respir. J. 8, 483-491.

Belanger, K., Gent, J.F., Triche, E.W., Bracken, M.B., Leaderer, B.P., 2006. Association of indoor nitrogen dioxide exposure with respiratory symptoms in children with asthma. Am. J. Respir. Crit. Care Med. 173, 297-303.

Belanger, K., Holford, T.R., Gent, J.F., Hill, M.E., Kezik, J.M., Leaderer, B.P., 2013. Household levels of nitrogen dioxide and pediatric asthma severity. Epidemiology 24, 320-330.

Breysse, P.N., Diette, G.B., Matsui, E.C., Butz, A.M., Hansel, N.N., McCormack, M.C., 2010. Indoor air pollution and asthma in children. Proc. Am. Thorac. Soc. 7, 102-106.

Cibella, F., Cuttitta, G., La Grutta, S., Melis, M.R., Lospalluti, M.L., Uasuf, C.G., Bucchieri, S., Viegi, G., 2011. Proportional Venn diagram and determinants of allergic respiratory diseases in Italian adolescents. Pediatr. Allergy Immunol. 22, 60-68.

Cyrys, J., Heinrich, J., Richter, K., Wölke, G., Wichmann, H.E., 2000. Sources and concentrations of indoor nitrogen dioxide in Hamburg (west Germany) and Erfurt (east Germany). Sci. Total Environ. 250, 51-62.

Flamant-Hulin, M., Caillaud, D., Sacco, P., Penard-Morand, C., Annesi-Maesano, I., 2010. Air pollution and increased levels of fractional exhaled nitric oxide in children with no history of airway damage. J. Toxicol. Environ. Health A 73, 272-283.

Garrett, M.H., Hooper, M.A., Hooper, B.M., Abramson, M.J., 1998. Respiratory symptoms in children and indoor exposure to nitrogen dioxide and gas stoves. Am. J. Respir. Crit. Care Med. 158, 891-895.

Gillespie-Bennett, J., Pierse, N., Wickens, K., Crane, J., Howden-Chapman, P., 2011. The respiratory health effects of nitrogen dioxide in children with asthma. Eur Respir. J. 38, 303-309.

Hansel, N.N., Breysse, P.N., McCormack, M.C., Matsui, E.C., Curtin-Brosnan, J., Williams, D.L., Moore, J.L., Cuhran, J.L., Diette, G.B., 2008. A longitudinal study of indoor nitrogen dioxide levels and respiratory symptoms in inner-city children with asthma. Environ. Health Perspect. 116, 1428-1432.

Jarvis, D., Chinn, S., Luczynska, C., Burney, P., 1996. Association of respiratory symptoms and lung function in young adults with use of domestic gas appliances. Lancet 347, 426-431.

Kattan, M., Gergen, P.J., Eggleston, P., Visness, C.M., Mitchell, H.E., 2007. Health effects of indoor nitrogen dioxide and passive smoking on urban asthmatic children. J. Allergy Clin. Immunol. 120, 618-624.

Kuehni, C.E., Strippoli, M.P., Zwahlen, M., Silverman, M., 2006. Association between reported exposure to road traffic and respiratory symptoms in children: evidence of bias. Int. J. Epidemiol. 35, 779-786.

Klepeis, N.E., Nelson, W.C., Ott, W.R., Robinson, J.P., Tsang, A.M., Switzer, P., Behar, J. V., Hern, S.C., Engelmann, W.H., 2001. The National Human Activity Pattern Survey (NHAPS): a resource for assessing exposure to environmental pollutants. J. Expo. Anal. Environ. Epidemiol. 11, 231-235.

Lee, K., Xue, J., Geyh, A.S., Ozkaynak, H., Leaderer, B.P., Weschler, C.J., Spengler, J.D., 2002. Nitrous acid, nitrogen dioxide, and ozone concentrations in residential environments. Environ. Health Perspect. 110, 145-150.

Lin, W., Brunekreef, B., Gehring, U., 2013. Meta-analysis of the effects of indoor nitrogen dioxide and gas cooking on asthma and wheeze in children. Int. J. Epidemiol. 42, 1724-1737.

Melki, I.S., Beydoun, H.A., Khogali, M., Tamim, H., Yunis, K.A., 2004. Household crowding index: a correlate of socioeconomic status and inter-pregnancy spacing in an urban setting. J. Epidemiol. Community Health 58, 476-480.

Miller, M.R., Hankinson, J., Brusasco, V., Burgos, F., Casaburi, R., Coates, A., Crapo, R. Enright, P., van der Grinten, C.P., Gustafsson, P., Jensen, R., Johnson, D.C., MacIntyre, N., McKay, R., Navajas, D., Pedersen, O.F., Pellegrino, R., Viegi, G., Wanger, J., 2005. Standardisation of spirometry. Eur. Respir. J 26, 319-338.

Neas, L.M., Dockery, D.W., Ware, J.H., Spengler, J.D., Speizer, F.E., Ferris Jr., B.G., 1991. Association of indoor nitrogen dioxide with respiratory symptoms and pulmonary function in children. Am. J. Epidemiol. 134, 204-219.

Nuvolone, D., Della Maggiore, R., Maio, S., Fresco, R., Baldacci, S., Carrozzi, L., Pistelli, F., Viegi, G., 2011. Geographical information system and environmental epidemiology: a cross-sectional spatial analysis of the effects of traffic-related air pollution on population respiratory health. Environ. Health 10, 12.

Piro, F.N., Madsen, C., Naess, O., Nafstad, P., Claussen, B., 2008. A comparison of selfreported air pollution problems and GIS-modeled levels of air pollution in people with and without chronic diseases. Environ. Health 7, 9.

Quanjer, P.H., Stanojevic, S., Cole, T.J., Baur, X., Hall, G.L., Culver, B.H., Enright, P.L., 
Hankinson, B.P., Ip, M.S., Zheng, J., Stocks, J., 2012. Multi-ethnic reference values for spirometry for the 3-95 years age range: the global lung function 2012 equations. Eur. Respir. J. 40, 1324-1343.

Rosenlund, M., Forastiere, F., Porta, D., De Sario, M., Badaloni, C., Perucci, C.A., 2009. Traffic-related air pollution in relation to respiratory symptoms, allergic sensitisation and lung function in schoolchildren. Thorax 64, 573-580.

Sakai, K., Norbäck, D., Mi, Y., Shibata, E., Kamijima, M., Yamada, T., Takeuchi, Y. 2004. A comparison of indoor air pollutants in Japan and Sweden: formaldehyde, nitrogen dioxide, and chlorinated volatile organic compounds. Environ. Res. 94, 75-85.

Simoni, M., Carrozzi, L., Baldacci, S., Scognamiglio, A., Di Pede, F., Sapigni, T., Viegi, G., 2002. The Po River Delta (north Italy) indoor epidemiological study: effects of pollutant exposure on acute respiratory symptoms and respiratory function in adults. Arch. Environ. Health 57, 130-136.

Simoni, M., Annesi-Maesano, I., Sigsgaard, T., Norback, D., Wieslander, G., Nystad, W., Canciani, M., Sestini, P., Viegi, G., 2010. School air quality related to dry cough, rhinitis and nasal patency in children. Eur. Respir. J. 35, 742-749.

Simoni, M., Cai, G.H., Norback, D., Annesi-Maesano, I., Lavaud, F., Sigsgaard, T., Wieslander, G., Nystad, W., Canciani, M., Viegi, G., Sestini, P., 2011. Total viable molds and fungal DNA in classrooms and association with respiratory health and pulmonary function of European schoolchildren. Pediatr. Allergy Immunol. $22,843-852$.

The European Academy of Allergology and Clinical Immunology, 1993. Position paper: allergen standardization and skin tests. Allergy 48, 48-82.

Tramuto, F., Cusimano, R., Cerame, G., Vultaggio, M., Calamusa, G., Maida, C.M., Vitale, F., 2011. Urban air pollution and emergency room admissions for respiratory symptoms: a case-crossover study in Palermo, Italy. Environ. Health $10,31-41$.

van Strien, R.T., Gent, J.F., Belanger, K., Triche, E., Bracken, M.B., Leaderer, B.P., 2004. Exposure to $\mathrm{NO}_{2}$ and nitrous acid and respiratory symptoms in the first year of life. Epidemiology 15, 471-478.

WHO, 2010. WHO Guidelines for Indoor Air Quality: Selected Pollutants. WHO European Centre for Environment and Health, Bonn Office, World Health Organization. Available: 〈http://www.euro.who.int/_data/assets/pdf_file/0009/ 128169/e94535.pdf (last accessed September, 2014). 